\section{Fossils for beginners}

Alec Panchen

Vertebrate Palaeontology: Biology and Evolution. By Michael J. Benton. Hyman 1990. Pp.377. Hbk £45; pbk £14.95.

A FEW years ago a debate was staged at the annual meeting of British vertebrate palaeontologists to discuss the question "What is vertebrate palaeontology for?" It was not an unqualified success, rapidly degenerating into the usual scientists exchange about inadequate funding, but the question remains an important one. Should students of vertebrate fossils be concerned solely with an attempt to reconstruct the anatomy and way of life of the cxtinct creatures that pre-occupy them, thus to produce a reconstructed phylogeny and narrative history of the group, or should they also aim for a conscious input from their studies to evolutionary theory and historiography as well as to history of the Earth's biota?

The traditional response has been to duck the question. For about fifty years the standard text and reference was Romer's Vertebrate Paleontology which raised the narrative tradition to a high level. Its successor is Carroll's Vertebrate Paleontology and Evolution with a format closely modelled on Romer, but with more latitude given to controversy and more overt reference to primary sources. But the aims are the same, and so they are in Michael Benton's Vertebrate Palaeontology, Biology and Evolution, which is intended for a less palaeontologically sophisticated audience than Carroll. Within its limits it is very successful. It is written in a clear and engaging style and is well referenced and generally up-to-date. The illustrations, all line drawings, are mostly skeletal reconstructions of fossils, but with cladograms, evolutionary trees, diagrams of living organisms and palaeogeographical reconstructions as appropriate. All are useful and adequately presented. In the text, Benton opts for a cladistic approach to vertebrate classification, as do most vertebrate palaeontologists, but I rather doubt whether his brief and uncharacteristically opaque account of cladistic methods is adequate as background for their use in the rest of the book. The order of chapters is a compromise between the traditional taxonomic sequence, origin of vertebrates and Agnatha first, human evolution last, and one of geological time, so that postDevonian fishes come after Triassic reptiles. But it would be wrong to give the impression that the book is just one damned fossil after another. Descriptive sections are interspersed with brief but lucid accounts of famous fossil communities, extinction events, phylogenetic summaries and so on. Overall it presents an interesting account of the parade of vertebrate history.

But still the narrative tradition is not breached. I can imagine two other kinds of vertebrate palaeontology text which might command a wider, or at least a different audience. The first would concentrate on the methods, not just the practical techniques but also the modes of thought, of vertebrate palaeontologists. Symptomatic would be the illustration, perhaps as photographs, of actual fossil specimens in all their imperfection. It is ironical that for such information one has to turn to books written for a mass audience, notably those on dinosaurs. The second kind of text would try to tackle our question "What is vertebrate palaeontology for?" It would discuss the nature and validity of data and hypotheses from vertebrate palaeontology as contributions to the debate on systematics, the patterns and processes of phylogeny, the causes of mass extinction, the nature and significance of fossil communities and other con-

\section{Flights of fancy}

\section{Grahame Hardie}

Identification of Protein Consensus Sequences. By Alastair Aitken. Horwood: 1990. Pp. 167. £31.

ThE determination of the complete sequence of a genome represents the end of one phase of research, but also the beginning of a new, more interesting phase. The computer can quickly assign those curious creatures called open reading frames (ORFs) which encode the putative proteins of the organism. Eventually functions may be assigned to these on the basis of similarity with proteins which have been sequenced independently. But an amino-acid sequence remains a bland specimen unless it can be garnished with trimmings: active-site domains, prosthetic group and bindingsite motifs, and sites of processing and post-translational modification.

For those with a need to enliven such a dull sequence, this book serves a dual purpose. First, it presents a review of motifs such as potential phosphorylation sites, CAAX boxes and zinc fingers with which speculatively to adorn your sequence. Second, when the journal editor demands some evidence for your flights of fancy, it provides brief practical details, and lists of references, to enable you to obtain it.

The book is particularly valuable for its discussion of post-translational modifications, of which over a hundred have now been described, including phosphoryla- troversies where the lead has been taken by nonvertebrate palaeontologists.

Benton's book fits neither of these patterns, but nevertheless is an introduction to vertebrate history which might well fire the imagination of students that will go on to study these weightier problems.

Alec Panchen is Reader in Vertebrate Zoology, Department of Biology, University of Newcastle upon Tyne, NE1 7RU, UK.

- Paleontology of Vertebrates by Jean Chaline describes the evolution of all of the major vertebrate groups from the Agnatha to the hominids, taking a cladistic approach throughout. Also discussed are modes of fossilization, palaeontological techniques, the species concept and the place of palaeontology in evolutionary biology as a whole. Published by Springer, price $\$ 29.50$. New out in paperback is Evolution and the Fossil Record edited by Keith Allen and Derek Briggs (for review, see Nature 340,$684 ; 1989$ ). The book is concerned with the many aspects of evolution that can only be tackled using evidence gleaned from the fossil record. Published by Smithsonian Institution Press, price $\$ 19.95$ (also available in hardback, price $\$ 49.95$ ).

tion (on serine, threonine, tyrosine or histidine), attachment of various lipids (acetyl, myristoyl, palmitoyl or polyisoprenoids), and carbohydrates (glycosyl groups and glycosyl-phosphatidylinositol membrane anchors). These modifications are often difficult to identify on automated amino-acid sequenators, and $\mathrm{N}$-terminal modifications may preclude their use altogether. The author describes the various technical tricks required to overcome these problems, as well as discussing alternative approaches such as the fast-atom bombardment-mass spectrometer. In other chapters he discusses primary structure motifs such as kinase and protease active sites, metal-binding sites and disulphide bridged repeats. In a book of this length the coverage of such a large topic could not be comprehensive, and the would-be theoretical biochemist armed with his genome sequence and computer terminal will find the book to be a useful introduction rather than a bible. Nevertheless, all of the currently fashionable motifs, such as leucine zippers, GTPbinding sites, EGF-like regions and kringles are discussed. A useful appendix provides a concise listing of the motifs and consensus sequences discussed earlier in the book. Overall, the author has performed a valuable service in bringing together information which is otherwise scattered throughout the biochemical literature, and I feel sure that the book would not remain undisturbed on its library or laboratory shelf for long periods.

Grahame Hardie is in the Biochemistry Department. The University, Dundee DD1 4HN, UK. 